\title{
Japan leaning towards SSC
}

\section{Tokyo}

As Japan heads into 1992, it faces two important, related issues: the increasingly urgent calls for reform and renovation of its university research system, and the question of how to respond to US requests for help in building the Superconducting Super Collider (SSC).

On the second issue, a preliminary decision seems to have been made. It now seems almost certain that Prime Minister Kiichi Miyazawa will promise financial support for the SSC when US President George Bush visits Japan next week (7-10 January). Miyazawa's message of support will come despite widespread opposition in the Japanese government bureaucracy and academic institutions to helping support the SSC. The SSC is now estimated to cost $\$ 8,500$ million, and the US Administration is seeking about $\$ 1,000$ million from Japan.

Officials of Japan's science-related ministries and agencies have made it plain to senior US officials who have visited Japan in the past few months that Japanese government organizations cannot afford to contribute to the SSC out of their limited budgets. And government officials have repeatedly explained to their US counterparts that the priority for Japan at present is domestic reform and renovation of the university research system.

Nevertheless, Miyazawa seems determined to press ahead with support for the
SSC. In mid-December, the Miyazawa administration made an abortive attempt to introduce taxes in 1992 to fund contributions to international activities, including Japanese participation in the SSC. But the proposal to raise $¥ 500,000$ million ( $\$ 3,800$ million) in extra taxes ran into a wall of opposition from industry and even from the ranks of Miyazawa's own ruling Liberal Democratic Party (LDP), partly because it included an attempt to continue temporary taxes on petroleum products and cars. The temporary taxes were introduced to help fund Japan's contribution to the Gulf War on the understanding that they would last only one year.

Undaunted, Miyazawa now says funds for the SSC will somehow be included in the 1993 budget. But just how this will be done without cutting into other budgets, no one knows.

While Miyazawa was trying to raise hundreds of millions of dollars for the SSC, officials of Japan's Ministry of Education, Science and Culture (Monbusho) were burning the midnight oil last week in last-minute negotiations with the Ministry of Finance trying to obtain about $\$ 100$ million in fiscal year 1992 to start renovating Japan's universities. Pressure from industry and universities to reform and rebuild Japan's universities - in particular, Tokyo University - has reached a critical point, and the ministry of education has at last started to request extra funds for the university research system.

A powerful new science pressure group has recently been formed within the LDP headed by Kishiro Nakamura, a former head of the Science and Technology Agency, to push forward renovation of the national laboratories and universities and the internationalization of Japan's science. On 26 December, Miyazawa told Nakamura that he expects that Bush will request the formation of a US-Japan working group on the SSC and Miyazawa would like to cooperate with the United States.

However, the position of Nakamura's committee on the SSC is equivocal. On 19 December the committee issued a statement saying that the collider will be the most advanced facility in the world, that it will contribute to fundamental understanding of the Universe and materials, and that how Japan deals with the SSC issue will have a fundamental bearing on the future of Japan's global partnership with the United States. But the committee then went on to say that to achieve the right environment for cooperation on the SSC and other international projects, the science-related ministries and agencies must first give urgent priority to improving the research base in the universities and national research laboratories.

No matter what the committee's position is, most science-related officials feel that Miyazawa will make some promise of support for the SSC, but it seems unlikely that he will be able to put a dollar figure on the Japanese contribution or say where it will come from.

David Swinbanks

\section{Large Hadron Collider moves ahead}

\section{London}

As the United States tries to find help paying for the SSC (see above), plans to build a similar machine at CERN, the European particle physics laboratory in Geneva, are gathering pace. The Large Hadron Collider (LHC) would be much less expensive than the SSC - around $\mathrm{SFr} 2,000$ million (about $\$ 1,400$ million) - because it will be built in the tunnel housing CERN's existing Large ElectronPositron collider. Director-general Carlo Rubbia says he is confident that the LHC can be built without increasing CERN's total budget, but the two detectors planned for the machine must be paid for separately, and are expected to cost at least another SFr600 million (about $\$ 425$ million).

In Germany and Britain, the cost of the LHC has been causing some anxiety. Before a meeting at CERN in late December, where Rubbia expounded the LHC's merits to a gathering of senior European science policy makers, there was concern that the German and British doubts would delay progress. But Rubbia is now in an ebullient mood, having won the backing from the CERN member states to continue with research on the LHC's magnets, and to choose the detectors for the machine.

At the insistence of Britain and Germany, Rubbia must produce acceptable blueprints for the detectors before winning final approval for the LHC, which will defer that decision until late 1993. But, given the problems experienced at SSC with the selection of detectors (which was left until after the main design had been approved), Rubbia is happy with the timetable he has been given. He says it is important to develop a collider and detectors that together will produce good science, rather than first designing a machine that will "go into the Guinness Book of Records" and then thinking about the programme of experiments. "Our friends across the Atlantic neglected this," Rubbia says.

Work on choosing the detectors for the LHC will begin in March, at a meeting in Evian-les-Bains in France. At present there are four designs competing for two detec- tor slots, and CERN's management hopes that the issue can be decided without the controversy that has surrounded the SSC's detectors.

Rubbia has also been asked to trawl for financial contributions towards the LHC from countries that are not CERN members. He believes he has a good case, as physicists from non-member states make up a quarter of those working at the laboratory. "We're totally overbooked, and many people from the member states are complaining," says Rubbia, suggesting that non-member countries may find it difficult to obtain time for their physicists at CERN in future, if they do not contribute towards the LHC. Rubbia does not intend to ask the United States for donations - he is happy with the reciprocal exchange of scientists between CERN and the United States, and says there is no need for money to change hands - but most other countries whose physicists use CERN can expect to hear from Rubbia over the coming year.

Peter Aldhous 